\title{
Formation of Discrete Silica Microspheres with Cysteamine and Cetyltrimethylammonium Bromide
}

\author{
Ji Hun Park and Insung S. Choi* \\ Molecular-Level Interface Research Center, Department of Chemistry, KAIST, Daejeon 305-701, Korea \\ *E-mail: ischoi@kaist.ac.kr \\ Received March 29, 2010, Accepted May 12, 2010
}

Key Words: Cetyltrimethylammonium bromide, Cysteamine, Glass sponge, Silicification, Silica

In biomimetic silicification, we abstract essential factors from biosilicification occurring in nature (i.e., biogenic silica formation) in the mechanistic aspects and apply them to the anthropogenic synthesis of silica under mild conditions in the controllable way. For example, our group reported that poly(2(dimethylamino)ethyl methacrylate) and its quaternized form chemically mimicked silaffins, which were found in diatoms, ${ }^{1}$ and acted as a catalytic template for the size-controlled synthesis of silica and titanium oxide thin films. ${ }^{2}$ In addition, the biomimetic strategy was combined with a technique of layerby-layer self-assembly to encapsulate individual living yeast cells with silica; ${ }^{3}$ as expected, the biomimetic synthesis of silica was achieved under physiologically favorable conditions (i.e., ambient pressure, room temperature or below, and near neutral $\mathrm{pH}$ values), and it, therefore, proved advantageous over the conventional sol-gel process especially when dealing with biological entities, such as proteins and cells. ${ }^{4}$ Other groups also have studied the biomimetic approach to the synthesis of silica particles and thin films based on biosilicification of diatoms. ${ }^{5}$

Compared with diatoms, glass sponges, another silica-forming species, have been studied relatively less in the chemistry point of view, ${ }^{6}$ although catalytic proteins, called silicateins (silica proteins), were identified, and their catalytic mechanism was suggested in the late nineties: ${ }^{6 \mathrm{~d}}$ serine-26 and histidine- 165 in silicateins were reported to be required for their catalytic activity. ${ }^{6 \mathrm{c}}$ In other words, the biosilicification in glass sponges was thought to involve the nucleophilic attack of the $\mathrm{OH}$ group to silicon alkoxide assisted by hydrogen bonding of imidazole to the $\mathrm{OH}$ group. Based on the proposed mechanism, Morse et al. reported that certain small molecules, such as cysteamine $\left(\mathrm{HSCH}_{2} \mathrm{CH}_{2} \mathrm{NH}_{2}\right)$, were catalytically active for silica synthesis from silicon alkoxides at neutral $\mathrm{pH} .{ }^{6 \mathrm{~b}}$ However, the silica structures formed by these biomimetic catalysts were not individually separated, discrete silica particles but interconnected aggregates of silica particulates. Considering the wide range of applications of discrete silica particles, ${ }^{7}$ we thought that the biomimetic approach, performed under mild reaction conditions, would be advantageous over or complementary to the conventional Stöber method that generally requires harsh conditions. Especially, the formation of relatively pure silica particles would be anticipated in the mimicry of the biosilicification of glass sponges, while silica/organic hybrids were formed by silicification mimicking diatoms. In this Communication, we demonstrated that the simple addition of a surfactant, cetyltrimethylammonium bromide (CTAB), to the Morse's protocol led to the formation of discrete silica microspheres.

The synthetic procedures are shown in Figure 1. The final concentration of cysteamine was fixed to be $50 \mathrm{mM}$ by following the Morse's conditions, and that of tetraethyl orthosilicate $\left(\mathrm{Si}(\mathrm{OEt})_{4}\right.$; TEOS) to be $120 \mathrm{mM}$, after our optimization (we optimized the concentration for this and other systems, and will publish a full description later in a separate paper). The 5-mM CTAB was used, and the ratio of water and ethanol was varied. To a mixture of cysteamine and CTAB in a water-ethanol system was added TEOS with vigorous shaking, and the silicification was carried out at ambient temperature without shaking/stirring. The initial $\mathrm{pH}$ was measured to be about 8 . A white precipitate was observable in about 45 min with the naked eye. After $3 \mathrm{~h}$, the resulting precipitates were washed with ethanol several times, dispersed in ethanol by sonication, and characterized by field-emission scanning electron microscopy (FE-SEM).

In the FE-SEM micrographs we clearly observed individually separated silica microspheres (formed in the 0.6:1 (v/v) mixture solution of water and ethanol) (Figure 2a). The shape-uniformity was noticeable, and the surface was remarkably smooth, although we occasionally observed small nanoparticles with diameter less than $150 \mathrm{~nm}$. We measured the diameter of at least 250 microspheres, and the average diameter was calculated to be $1.03 \pm 0.05 \mu \mathrm{m}$. In comparison, Morse observed the interconnected aggregates of silica particulates with the diameter ranging from 40 to $100 \mathrm{~nm}$. It is noteworthy that the biomimetic approaches have generated only sub-micrometer-scaled silica particles so far. ${ }^{1 \mathrm{~b}, 5 \mathrm{c}}$ At this moment, the role of CTAB in the observed size increase remains to be seen, but CTAB clearly worked as an "insulating" agent, leading to the formation of

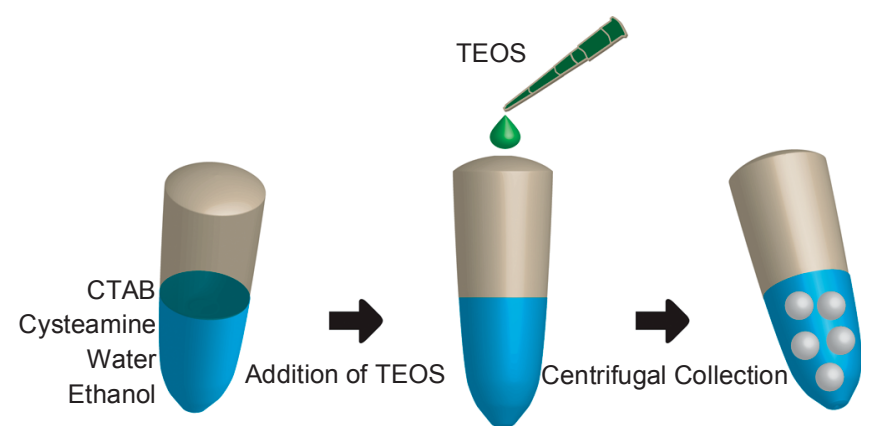

Figure 1. Schematic representation of the synthetic procedures. 


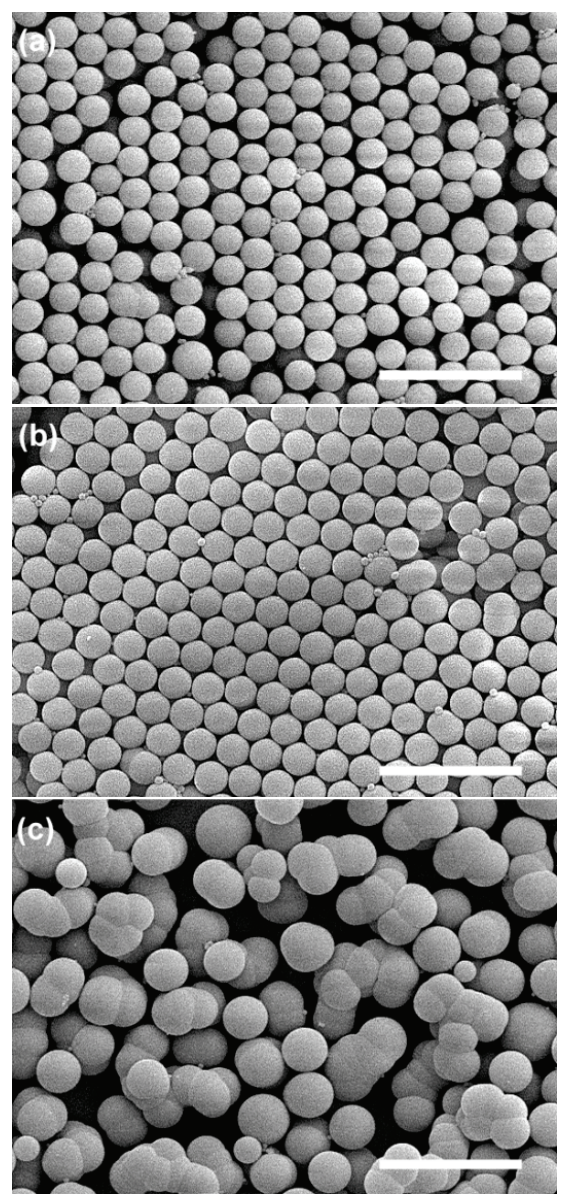

Figure 2. FE-SEM micrographs of silica structures. The volume ratio of water to ethanol: (a) $0.6: 1$, (b) $0.8: 1$, and (c) $1: 1$. The scale bar is $5 \mu \mathrm{m}$.

discrete silica microspheres.

We found that a slight change in the ratio of water and ethanol dramatically changed the size and morphology of silica. For example, when we increased the ratio from $0.6: 1$ to $0.8: 1$, we observed that the size of silica microspheres was increased to $1.25 \pm 0.08 \mu \mathrm{m}$ (Figure $2 \mathrm{~b}$ ). The individual spheres were clearly separated from each other. However, further increase of the ratio to 1:1 yielded the interconnected aggregates of silica particles (Figure 2c). The size was increased to about $2.2 \mu \mathrm{m}$, and most of particles coalesced to form the oligomers. These results implied that many factors played roles in the formation of silica structures, and it would be feasible to generate a variety of structurally controlled silica by fine-tuning the reaction parameters and conditions. A systematic study on the control of silica structures will be our next research thrust.

In summary, we demonstrated that individually separated ("discrete") silica microspheres were synthesized by using cetyltrimethylammonium bromide as a shape-directing (probably "insulating") agent. Our synthetic procedure was based on the biomimetic approach to the silica formation, which utilizes small biomimetic catalysts at near neutral $\mathrm{pH}$; a control experiment with ethylene diamine as a catalyst also yielded oligomeric silica structures at the high $\mathrm{pH}$ value (about $\mathrm{pH} 12$ ). Although the near-neutral reaction condition (about $\mathrm{pH}$ 8) in our synthetic procedure provides the similar chemical environment to biological silicification, it could not be excluded completely that the silicification proceeded via the Stöber process. Further detailed studies would clarify the processes in the mechanistic aspects.

This communication is our proof-of-concept for the shapecontrolled synthesis of silica structures, and indicates that more structurally exquisite silica structures with various functions, hopefully equivalent to those found in nature, could be generated by varying/optimizing reaction parameters, such as silicon alkoxides, catalysts, surfactants/polymers, and reaction media. Biomimetic silica chemistry is still in its infancy, but we believe that it is full of possibility in controlled anthropogenic synthesis of silica and other metal oxide structures under ambient conditions.

Acknowledgments. This work was supported by the National Research Foundation of Korea (NRF) grant funded by the Korean government (MEST) (2009-008449 and 2010-0001953). J. H. Park thanks the POSCO TJ Park Foundation (TJ Park Doctoral Fellowship) for generous support.

\section{References}

1. (a) Sumper, M.; Brunner, E. Adv. Funct. Mater. 2006, 16, 17 and references therein. (b) Sumper, M.; Lorenz, S.; Brunner, E. Angew. Chem. Int. Ed. 2003, 42, 5192.

2. (a) Yang, S. H.; Park, J. H.; Cho, W. K.; Lee, H.-S.; Choi, I. S. Small 2009, 5, 1947. (b) Yang, S. H.; Kang, K.; Choi, I. S. Chem. Asian J. 2008, 3, 2097. (c) Kim, D. J.; Lee, K.-B.; Lee, T. G.; Shon, H. K.; Kim, W.-J.; Paik, H.-j.; Choi, I. S. Small 2005, 1, 992. (d) Kim, D. J.; Lee, K.-B; Chi, Y. S.; Kim, W.-J.; Paik, H.-j.; Choi, I. S. Langmuir 2004, $20,7904$.

3. (a) Yang, S. H.; Lee, K.-B.; Kong, B.; Kim, J.-H.; Kim, H.-S.; Choi, I. S. Angew. Chem. Int. Ed. 2009, 48, 9160. (b) Yang, S. H.; Park, J. H.; Choi, I. S. Bull. Korean Chem. Soc. 2009, 30, 2165. (c) Yang, S. H.; Choi, I. S. Chem. Asian J. 2009, 4, 382.

4. (a) Baca, H. K.; Ashley, C.; Lopez, C. D.; Flemming, J.; Dunphy, D.; Singh, S.; Chen, Z.; Liu, N.; Fan, H.; López, G. P.; Brozik, S. M.; Werner-Washburne, M.; Brinker, C. J. Science 2006, 313, 337. (b) Luckarift, H. R.; Spain, J. C.; Naik, R. R.; Stone, M. O. Nat. Biotechnol. 2004, 22, 211.

5. (a) Wu, J.-C.; Wang Y.; Chen, C.-C.; Chang, Y.-C. Chem. Mater. 2008, 20, 6148. (b) Tomczak, M. M.; Glawe, D. D.; Drummy, L. F.; Lawrence, C. G.; Stone, M. O.; Perry, C. C.; Pochan, D. J.; Deming, T. J.; Naik, R. R. J. Am. Chem. Soc. 2005, 127, 12577. (c) Knecht, M. R.; Sewell, S. L.; Wright, D. W. Langmuir 2005, 21, 2058.

6. (a) Brutchey, R. L.; Morse, D. E. Chem. Rev. 2008, 108, 4915 and references therein. (b) Roth, K. M.; Zhou, Y.; Yang, W.; Morse, D. E. J. Am. Chem. Soc. 2005, 127, 325. (c) Zhou, Y.; Shimizu, K.; Cha, J. N.; Stucky, G. D.; Morse, D. E. Angew. Chem. Int. Ed. 1999, 38, 780. (d) Cha, J. N.; Shimizu, K.; Zhou, Y.; Christiansen, S. C.; Chmelka, B. F; Stucky, G. D.; Morse, D. E. Proc. Natl. Acad. Sci. USA 1999, 96, 361.

7. (a) Jeong, U.; Wang, Y.; Ibisate, M.; Xia, Y. Adv. Funct. Mater. 2005, 15, 1907. (b) Nozawa, K.; Gailhanou, H.; Raison, L.; Panizza, P.; Ushiki, H.; Sellier, E.; Delvile, J. P.; Delville, M. H. Langmuir 2005, 21, 1516. 